\title{
Dimensões da abordagem histórica no Ensino de Ciências e de Matemática ${ }^{+}$
}

Zaqueu Vieira Oliveira ${ }^{1}$

Universidade Federal da Integração Latino-Americana

Foz do Iguaçu - PR

Márcia Helena Alvim ${ }^{1}$

Universidade Federal do ABC

Santo André - SP

\section{Resumo}

A História das Ciências e da Matemática tem sido apontada como uma das possíveis abordagens para o ensino e muitos têm sido os âmbitos destas discussões. Neste artigo, apresentamos uma proposta teórica acerca dessa interface que remete a três possiveis dimensões: a epistemológica, que é fundamentada nos debates acerca da natureza da Ciência; a sociocultural, que tem como foco as conexões entre história cultural das Ciências, sociologia das ausências e educação problematizadora; e a da práxis, que se baseia na proposta freiriana de temas geradores. Debatemos cada uma destas dimensões compreendendo a abordagem histórica com um enfoque interdisciplinar nas aulas de Ciências e de Matemática como forma de tornar os conteúdos compreensíveis e significativos para os estudantes.

Palavras-chave: Educação Problematizadora; Sociologia das Ausências; História das Ciências e Matemática; Ensino de Ciências e de Matemática.

\footnotetext{
Abstract

${ }^{+}$Dimensions of historical approaches in Science and Mathematics Education

* Recebido: junho de 2020. Aceito: novembro de 2020

${ }^{1}$ Emails: z.zaqueu@gmail.com e marcia.alvim@ufabc.edu.br
}

The History of Science and Mathematics has been identified as one of the possible approaches to teaching and there are different possible 
dimensions to it. In this article, we present a theoretical proposal about this interface that refers to three possible dimensions: the epistemological one, which is based on debates about the nature of Science; the sociocultural, which focuses on the connections between cultural history of sciences, sociology of absences, and problem-posing education; and that of praxis, which is based on the Freirean idea of generating themes. We discuss each of these dimensions reflecting on the historical approach with an interdisciplinary focus on Science and Mathematics classes as a way to make the scientific content understandable and meaningful to students.

Keywords: Problem-posing Education; Sociology of Absences; History of Science and Mathematics; Science and Mathematics Teaching.

\section{Introdução}

A abordagem histórica tem sido apontada como uma das formas possíveis para promover um Ensino de Ciências e de Matemática mais crítico e reflexivo, levando para a sala de aula diferentes aspectos do desenvolvimento e da prática científica e matemática ao longo da história (ALVIM; ZANOTELLO, 2014; BELTRAN, 2009; FAUVEL; MAANEN, 2002; FIGUEIRÔA, 2019; FORATO; GUERRA; BRAGA, 2014; MATTHEWS, 1995; 2018; MIGUEL, 1997; PRESTES; SILVA, 2018; ROQUE, 2014; SAITO, 2010; SILVA; PRESTES, 2013). Embora não haja um consenso, assumimos que essa abordagem tem o potencial de fazer com que os estudantes compreendam diferentes aspectos do conteúdo que lhes está sendo ensinado, assim como percebam a importância dos conhecimentos científicos e matemáticos para sua formação como cidadão.

Diversos estudos mostram que, através da reflexão histórica, seria possível a sensibilização dos estudantes quanto à natureza da Ciência (ACEVEDO et al., 2005; KIPNIS, 2002; MARTINS, 2015; MATTHEWS, 1995; MOURA, 2014; OKI; MORADILLO, 2008; SILVA, PRESTES, 2013), aos aspectos socioculturais da prática científica e matemática (ALVIM; ZANOTELLO, 2014; D’AMBRÓSIO, 2001; MOURA; GUERRA, 2016; GERDES, 1991; KELLY; CARLSEN; CUNNINGHAN, 1993; PIMENTEL, 2010) e uma perspectiva interdisciplinar dos conteúdos (BELTRAN; TRINDADE, 2017; FAZENDA, 1979, 2008; TRINDADE, 2008). Esta reflexão só é possível através de uma prática docente que leve os estudantes a refletirem historicamente acerca das Ciências e da Matemática fazendo-os compreenderem os conteúdos que estão aprendendo (FAZENDA, 2008; FREIRE, 1974), além de discutirem como ocorre o desenvolvimento desses conhecimentos na comunidade científica e matemática e conhecerem o papel destas áreas na sociedade, possibilitando sua participação como cidadãos. 
Este é o objetivo deste artigo: analisar algumas relevantes dimensões da discussão histórica quando de sua inserção no Ensino de Ciências e de Matemática. Como uma proposta teórica, buscaremos aqui apresentar uma análise crítica de diferentes abordagens sobre a relação entre História das Ciências e da Matemática e Ensino, bem como propor uma organização em três diferentes âmbitos das possibilidades estudadas. Os aspectos aqui discutidos foram pensados a partir de reflexões realizadas pelos autores quando da análise sobre as possibilidades teórico-pedagógicas da inserção da História das Ciências na educação científica. Deste modo, como todo recorte teórico e metodológico, outras importantes reflexões não foram aqui contempladas, mas salientamos a relevância e a articulação desta proposta em relação a recente discussão sobre a História das Ciências e da Matemática e o Ensino.

Essa proposta visa apresentar alguns apontamentos acerca da prática docente como mediadora no processo de inserção da abordagem histórica em sala de aula. Este debate ocorrerá a partir do que denominaremos de dimensões, ou seja, os âmbitos em que esse debate pode ser travado. Salientamos, de antemão, que as discussões apresentadas nas três dimensões devem ser pensadas de modo indissociável no processo educativo, a "separação" aqui proposta visa somente facilitar a compreensão de toda a complexidade relativa ao tema.

Cada uma das dimensões é formulada a partir de justificativas que nos remetem às discussões teóricas já estabelecidas e amplamente defendidas por diversos pesquisadores. As dimensões e sua respectiva justificativa serão debatidas a partir de um enfoque interdisciplinar, tendo em vista uma ampla gama de pesquisas que defendem esta abordagem no Ensino de Ciências e de Matemática.

As dimensões aqui propostas e analisadas são as seguintes:

- Dimensão epistemológica: trata da importância de abordar questões relacionadas à natureza do trabalho científico e matemático, que entendemos como os modos de se produzir e praticar as Ciências e a Matemática;

- Dimensão sociocultural: aborda a relevância das questões sociais e culturais que influenciaram (e influenciam) o desenvolvimento do conhecimento científico e matemático ao longo da história;

- Dimensão da práxis: apresenta a discussão sobre como a prática docente no Ensino de Ciências e de Matemática deve levar em consideração a realidade e os interesses dos alunos, tanto quanto a historicidade das Ciências, como forma de tornar os conteúdos compreensíveis e significativos, assim como gerar possibilidades de desenvolvimento de cidadania científica e matemática.

A dimensão epistemológica é fundamentada, principalmente, com base nos debates a respeito da natureza da Ciência (ACEVEDO et al., 2005; MARTINS, 2015; MOURA, 2014; SILVA, PRESTES, 2013). Já a dimensão sociocultural está estruturada a partir das discussões a respeito da história cultural das Ciências (PIMENTEL, 2010; ALVIM; ZANOTELLO, 2014; MOURA, GUERRA, 2016), da sociologia das ausências (SANTOS, 2002; 2011) e da 
educação problematizadora (FREIRE, 1974). E, por fim, a dimensão da práxis se baseia na ideia de temas geradores (FREIRE, 1974). As referências utilizadas servem somente como direcionadores para a construção de cada uma das dimensões.

Deste modo, é importante considerar dois aspectos: o fato de que as dimensões são indissociáveis entre si, como dissemos anteriormente; os conceitos citados não devem ser simplificados e restritos às dimensões aqui propostas, mas usamos tais ideias para fundamentar e justificar a importância de cada uma destas dimensões tendo em vista os aspectos que consideramos importantes na abordagem histórica nas aulas de Ciências e de Matemática.

A seguir, discutimos cada uma dessas dimensões reforçando a importância da abordagem histórica para o Ensino de Ciências e de Matemática. Em seguida, apresentamos, do ponto de vista teórico, um exemplo de conteúdo que permeia tanto as aulas de Ciências como as de Matemática, demostrando como ele pode ser trabalhado de modo interdisciplinar a partir da abordagem histórica e das dimensões aqui apresentadas. Enfatizamos que não apresentaremos uma proposta didática ou seremos prescritivos. O exemplo discutido constitui-se como uma possibilidade de reflexão teórica sobre as dimensões aqui apresentadas e como as mesmas permeiam um conteúdo curricular da Educação Básica. Por fim, tecermos algumas considerações sobre as conexões entre as dimensões propostas.

\section{Dimensão epistemológica da abordagem histórica}

Embora nas últimas décadas tenham ocorrido mudanças significativas no Ensino de Ciências e de Matemática, ainda assim, o foco tem sido, em sua maioria, nos sistemas de avaliação e nos vestibulares para ingresso no Ensino Superior fazendo com que estas disciplinas sejam apresentadas de forma mecânica - valorizando algoritmos, fórmulas e definições - e, muitas das vezes, os estudantes não veem sentido no que estão aprendendo (CACHAPUZ et al., 2005; FOUREZ, 2003; GÓMEZ-GRANELL, 1997). Assim, pesquisas realizadas no campo do Ensino de Ciências e de Matemática têm promovido intensos debates sobre a importância de uma abordagem integrada do conhecimento para que o aluno tenha um melhor êxito na compreensão dos conteúdos propostos em sala de aula (COUTO, 2011; FAZENDA, 1979; FOUREZ, 2008).

Para indicar essa integração entre conteúdos de disciplinas distintas, diversos autores utilizam principalmente a palavra interdisciplinaridade, porém percebe-se que há diversas acepções para o termo, algumas das quais exploraremos aqui com o intuito de relacioná-la com a reflexão histórica nas aulas de Ciências e de Matemática.

De um ponto de vista histórico, as fronteiras do conhecimento nem sempre estiveram organizadas da maneira como as conhecemos atualmente. Ao olharmos, por exemplo, distintas classificações do conhecimento publicadas nos séculos XVI e XVII percebemos que o campo das disciplinas matemáticas englobava áreas que hoje estão completamente separadas: tomamos como exemplo o caso da astronomia e da óptica que atualmente possuem 
grande independência em relação à matemática, mas que naquele momento eram entendidas como parte dela (OLIVEIRA, 2015). Porém, os cursos de formação inicial de professores, por diversos motivos - como o fato das grades curriculares privilegiarem as discussões dos conteúdos em si e suas relações com aspectos didáticos e pedagógicos das respectivas disciplinas -, nem sempre promovem a análise dos aspectos históricos e filosóficos das disciplinas, de maneira que ideias e concepções estereotipadas - como, por exemplo, que as Ciências e a Matemática são campos de conhecimento imutáveis e estáticos - acabam por serem transmitidas aos alunos (GIL PÉREZ et al., 2001; HARRES, 1999; LEDERMAN, 1992; OKI; MORADILLO, 2008).

Com o passar do tempo, não somente o volume de estudos e de informações levantadas foi ficando maior, mas também o conhecimento científico e matemático ficou cada vez mais institucionalizado. Aos poucos, foi necessário criar novas subcategorias, "fatias do saber", que dessem conta de justificar as especificidades de cada subárea de pesquisa. Surgiu, então, a figura do especialista (JAPIASSU, 1976).

O filósofo francês Georges Gusdorf, no prefácio do livro Interdisciplinaridade e Patologia do Saber de Hilton Japiassu (1976), apontou que a especialização excessiva da ciência, da política, da economia e das diferentes áreas do saber trouxe enormes abismos. Para Gusdorf, se em parte esta superespecialização ajuda-nos a compreender fenômenos de modo cada vez mais aprofundado, esse mesmo fato afeta o modo de vida como a sociedade atual se depara e resolve seus problemas, de maneira que um fenômeno pode acabar perdendo suas conexões com o mundo e o humano (JAPIASSU, 1976) ${ }^{2}$.

Uma das definições para o termo interdisciplinaridade advém da classificação proposta por Eric Jantsch (1972) - posteriormente adaptada por Japiassu (1976) - que propõe níveis de interação entre as disciplinas. Segundo os autores (JANTSCH, 1972; JAPIASSU, 1976), podemos entender a relação entre as disciplinas em quatro níveis, sendo estes: multidisciplinaridade, pluridisciplinaridade, interdisciplinaridade e transdisciplinaridade, conforme quadro 1.

Para Jantsch (1972), uma relação de mesmo nível entre as disciplinas, como nas abordagens multi e pluridisciplinar, leva a um diálogo pouco profícuo entre distintas áreas do saber. "Cruzar as fronteiras disciplinares implica em uma abordagem de "força bruta" para reinterpretar conceitos e objetivos disciplinares (axiomáticos) à luz de um objetivo específico (disciplinar) e impor uma polarização rígida entre as disciplinas no mesmo nível" (JANTSCH, 1972, p. 107, tradução nossa). Nesta visão, a interdisciplinaridade é uma

\footnotetext{
2 Buscando retomar uma perspectiva integrada das Ciências e da Matemática, a partir da metade do século passado surgiram no campo das pesquisas acadêmicas projetos de colaboração entre as diferentes áreas, o que culminou anos mais tarde na criação de institutos de pesquisa interdisciplinares e também em estudos relacionados à Educação. Em âmbito nacional, para além das pesquisas com enfoque interdisciplinar, mais recentemente algumas universidades criaram cursos de Graduação e Pós-Graduação seguindo esta tendência. Citamos, por exemplo, as Licenciaturas Interdisciplinares oferecidas na Universidade Federal do ABC (UFABC), as diversas licenciaturas em Ciências Naturais e Exatas disponíveis em universidades públicas nacionais, assim como os Programas de Pós-Graduação Interunidades da Universidade de São Paulo (USP).
} 
aproximação entre as disciplinas através de uma ação coordenada e com objetivos bem definidos a partir do qual todas as disciplinas estarão envolvidas, pressupondo o diálogo e a cooperação entre profissionais de distintas áreas, sem a sobreposição de métodos de uma sobre a outra (JANTSCH, 1972).

Quadro 1 - Definição dos termos relacionados à disciplinaridade.

\begin{tabular}{|c|c|c|}
\hline Descrição geral & Tipo de sistema & Representação \\
\hline $\begin{array}{l}\text { Multidisciplinaridade: Gama de } \\
\text { disciplinas que propomos } \\
\text { simultaneamente, mas sem } \\
\text { estabelecer as relações que podem } \\
\text { haver entre elas. }\end{array}$ & \begin{tabular}{lr}
\multicolumn{2}{l}{ Sistema de um só nível } \\
e de objetivos \\
múltiplos; & nenhuma \\
cooperação. &
\end{tabular} & \\
\hline $\begin{array}{l}\text { Pluridisciplinaridade: } \\
\text { Justaposição de diversas } \\
\text { disciplinas situadas geralmente no } \\
\text { mesmo nível hierárquico e } \\
\text { agrupadas de modo a ressaltar as } \\
\text { relações existentes entre elas. }\end{array}$ & $\begin{array}{l}\text { Sistema de um só nível } \\
\text { e de objetivos } \\
\text { múltiplos; cooperação, } \\
\text { mas sem ordenação. }\end{array}$ & \\
\hline $\begin{array}{l}\text { Interdisciplinaridade: } \\
\text { Axiomática comum a um grupo } \\
\text { de disciplinas conexas e definida } \\
\text { no nível hierárquico } \\
\text { imediatamente superior, o que } \\
\text { introduz a noção de finalidade. }\end{array}$ & $\begin{array}{l}\text { Sistema de dois níveis } \\
\text { e de objetivos } \\
\text { múltiplos; coordenação } \\
\text { procedendo do nível } \\
\text { superior. }\end{array}$ & \\
\hline $\begin{array}{l}\text { Transdisciplinaridade: } \\
\text { Coordenação de todas as } \\
\text { disciplinas e interdisciplinas do } \\
\text { sistema de ensino inovado, sobre } \\
\text { a base de uma axiomática geral. }\end{array}$ & $\begin{array}{l}\text { Sistema de níveis e } \\
\text { objetivos múltiplos; } \\
\text { coordenação com vistas } \\
\text { a uma finalidade } \\
\text { comum dos sistemas. }\end{array}$ & \\
\hline
\end{tabular}

É neste sentido que apresentamos a primeira justificativa - que consideramos estar em uma dimensão epistemológica - para a inserção da abordagem histórica nas aulas de Ciências e de Matemática com enfoque interdisciplinar, pois, torna-se importante abordar questões relacionadas à natureza do trabalho científico e matemático mostrando aos estudantes como as distintas áreas de conhecimento se conectam e como elas se desenvolveram ao longo da história (MARTINS, 2015; MATTHEWS, 2018; MOURA, 2014; OKI; MORADILLO, 2008; TRINDADE, 2008). Enfatizamos que "O caráter interdisciplinar da história da ciência não aniquila o caráter necessariamente disciplinar do conhecimento científico" (TRINDADE, 2008, p. 65) e, por um momento, posicionaremos os aspectos formais dos conteúdos disciplinares em um segundo plano, na medida em que o foco se torna 
a compreensão sobre o fazer científico e matemático. Ao sairmos das fronteiras rígidas de cada disciplina e levarmos os alunos a se atentarem para as possíveis conexões entre elas, fazemos com que apreendam a importância dos questionamentos, da elaboração de hipóteses, dos modos de investigar e de raciocinar frente a um problema apresentado, numa perspectiva histórica, tanto quanto a valorização das diferentes maneiras de apresentarem suas justificativas e argumentações.

Estas discussões permeiam debates acerca da Natureza da Ciência (NdC), termo que não é facilmente definido. Segundo Acevedo et al. (2005, p. 123, tradução nossa) "A NdC é um metaconhecimento sobre a ciência, que provém das análises interdisciplinares feitas por especialistas em história, filosofia e sociologia da ciência, mas também por alguns cientistas". Estas discussões têm como objetivo compreender:

[...] o que é a ciência, seu funcionamento interno e externo, como se constrói e se desenvolve o conhecimento que produz, os métodos que usa para validar esse conhecimento, os valores envolvidos nas atividades cientificas, a natureza da comunidade cientifica, os vínculos com a tecnologia, as relações da sociedade com o sistema tecnocientífico e vice-versa, as contribuições deste a cultura e ao progresso da sociedade (ACEVEDO et al., 2005, p. 122-123, tradução nossa).

Moura (2014) reafirma que existem vários significados para o termo, apresentando uma possível definição.

\begin{abstract}
A natureza da Ciência é entendida como um conjunto de elementos que tratam da construção, estabelecimento e organização do conhecimento científico. Isto pode abranger desde questões internas, tais como método científico e relação entre experimento e teoria, até outras externas, como a influência de elementos sociais, culturais, religiosos e políticos na aceitação ou rejeição de ideias científicas (MOURA, 2014, p. 32).
\end{abstract}

Embora haja controvérsias (EFLIN; GLENNAN, REISCH, 1999), partimos dos cinco principais aspectos ditos consensuais, defendidos por alguns dos autores que tratam da natureza da Ciência: (i) A Ciência é mutável, dinâmica e tem como objetivo buscar explicar os fenômenos naturais; (ii) Não existe um método científico universal; (iii) A teoria não é consequência da observação/experimento e vice-versa; (iv) A Ciência é influenciada pelo contexto social, cultural, político etc., no qual ela é construída; e (v) Os cientistas utilizam imaginação, crenças pessoais, influências externas, entre outros para fazer Ciência (MOURA, 2014).

Entendemos que tais aspectos, como afirmam Acevedo et al. (2005), podem ser entendidos em um sentido amplo, e não somente no âmbito epistemológico. Porém, neste artigo, discutimos os pontos i, ii, iii e $\mathrm{v}$ na dimensão epistemológica por tratarem especificamente do que estamos denominando de natureza do trabalho científico (e de um universo mais amplo que incorporamos a Matemática). Além disso, optamos por abordar o 
ponto iv separadamente, pois, embora ele nos leve à discussão em um nível epistemológico, queremos ampliá-lo para uma dimensão sociocultural do desenvolvimento histórico das Ciências e da Matemática e, por isso, ele será tratado adiante.

Ao abordar as Ciências e a Matemática como conhecimentos mutáveis e dinâmicos (ponto i), temos a possibilidade de desmistificar a ideia de que estes conhecimentos são estáticos e acabados. Isso leva para a sala de aula a possibilidade de que os estudantes percebam que o conhecimento científico e matemático pode ser questionado e não deve ser tratado como dogmas a serem seguidos cegamente (GIL PÉREZ et al., 2001; MOURA, 2014).

Assim como a produção científica e matemática perpassa por transformações ao longo da história, o processo de ensino pode e deve estar impregnado dessa percepção, mostrando aos alunos que a cultura científica e matemática têm como um de seus princípios a possibilidade de questionamento, de contestação, de contra argumentação, gerando mudanças e transformações no conhecimento de acordo com o momento histórico no qual são constituídas.

As discussões em relação a um método científico (ponto ii) também são importantes, pois têm o potencial de apresentarem aos estudantes que, apesar de em diversos momentos cientistas e matemáticos terem que seguir protocolos, existem diferentes maneiras de se produzir novos conhecimentos nestas áreas de saber (EFLIN; GLENNAN; REISCH, 1999). Pode-se estudar o mesmo fenômeno de distintas formas, o que nos leva a pensar que, no ambiente de sala de aula, reside a possibilidade de se atuar interdisciplinarmente acerca de uma mesma temática.

É importante lembrar que o desenvolvimento de uma teoria não é fruto somente da observação de um determinado fenômeno ou fato ou de um experimento que trate da questão estudada (ponto iii). As pesquisas científicas dependem de outros fatores, como a abstração e a generalização a partir de estudos já realizados, ou então, o aprofundamento de um determinado aspecto de um conjunto maior de problemáticas já exploradas.

Em relação ao ponto v, sabemos que produzir Ciências e Matemática possui certa objetividade, ou seja, em muitos casos o cientista e o matemático precisam seguir protocolos de trabalho e metodologias específicas para atingir seus objetivos e produzirem uma pesquisa que seja aceita entre seus pares. Porém, torna-se necessário questionarmos como a subjetividade e a imaginação do pesquisador interferem na produção de conhecimentos (GIL PÉREZ et al., 2001). Neste sentido entendemos que o desenvolvimento das Ciências e da Matemática não pode acontecer completamente de forma objetiva, já que os sentimentos, as ideias, a criatividade, as crenças e as opiniões e os caminhos escolhidos pelo pesquisador.

Os cinco aspectos ditos consensuais - o ponto iv será discutido na seção seguinte são questionados por alguns autores. Eflin, Glennan e Reisch (1999) afirmam que:

O conceito de NdC [Natureza da Ciência] parece pressupor: (a) que existe uma natureza da ciência a ser descoberta e ensinada aos alunos; (b) que uma lista de 
princípios pode descrever a natureza da ciência; e (c) que para uma disciplina ser considerada uma ciência, cada um dos princípios deve ser verdadeiro para essa disciplina. Na linguagem filosófica, esta é uma visão essencialista da ciência, pois acredita-se que haja uma essência da natureza ou conjunto de critérios que descreve todas e apenas as atividades e investigações que contam como ciência. A maioria dos filósofos e educadores das ciências que consideraram esta questão concluiram que esta visão essencialista não pode ser mantida (EFLIN; GLENNAN; REISCH, 1999, p. 108, tradução nossa).

Os autores defendem que as Ciências são tão complexas que dificilmente teríamos a possibilidade de produzir uma lista com aspectos comuns entre as Ciências. O conceito de Semelhança Familiar (Family Ressemblance) proposto pelos pesquisadores indica que diferentes Ciências podem ter muito pouco em comum e, no máximo, é possível perceber algumas semelhanças entre Ciências próximas entre si. Outra discussão apresentada diz respeito à dificuldade de demarcar o que é ciência: "Alguns acreditam que teorias e práticas podem ser identificadas como mais ou menos científicas, enquanto alguns sustentam que não há distinção entre ciência e não ciência" (EFLIN; GLENNAN; REISCH, 1999, p. 112, tradução nossa).

Martins (2015, p. 710) afirma que há uma pluralidade de visões acerca da natureza da Ciência "a depender da origem, da experiência, da posição profissional e dos pressupostos (ontológicos, epistemológicos etc.) de quem fala". Na busca de formas que direcionem o que ensinar relativo à natureza da Ciência, o autor sugere o trabalho com dois eixos principais:

O primeiro eixo [denominado histórico e sociológico] agruparia temas relativos ao papel do individuo e da comunidade cientifica; a intersubjetividade; questões morais, éticas e políticas; influências históricas e sociais; ciência como parte da cultura; comunicação do conhecimento. O segundo eixo [chamado epistemológico], mais amplo, agruparia temas relativos à origem do conhecimento (experiência $x$ razão; papel da observação, da experiência, da lógica e do pensamento teórico; influência da teoria sobre o experimento), aos métodos, práticas, procedimentos e processos da ciência (coleta, análise e avaliação de dados; inferência, correlação e causalidade; modelagem em ciência; papel da imaginação e criatividade; natureza da explicação), e ao conteúdo/natureza do conhecimento produzido (papel de leis e teorias; noção de modelo; semelhanças e diferenças entre ciência e outras formas de conhecimento) (MARTINS, 2015, p. 718, colchetes nossos).

Os eixos propostos nos remetem às duas primeiras dimensões que estão sendo aqui discutidas - a epistemológica e a sociocultural. Martins (2015, p. 703) está interessado na discussão das visões consensuais de natureza da Ciência propondo "uma abordagem mais aberta, plural e heterogênea para lidar com o saber sobre a ciência no currículo escolar de ciências", enquanto neste estudo enfocamos em uma abordagem histórica com um enfoque interdisciplinar nas aulas de Ciências e de Matemática como forma de tornar os conteúdos compreensíveis e significativos para os estudantes. Destarte as diferenças nas propostas, 
ambas discutem a importante reflexão sobre a relação entre o Ensino de Ciências e uma perspectiva crítica sobre as Ciências.

Neste sentido, não estamos defendendo a elaboração de uma lista de ideias "adequadas" ou "não deformadas" (GIL PÉREZ et al., 2001) das Ciências e da Matemática, mas propomos que se leve para a sala de aula alguns dos aspectos ligados à natureza do trabalho científico. Assim como afirmam Alvim e Zanotello (2014, p. 350), é importante promover discussões que levem os estudantes á "construção de uma cultura científica". Os autores propõem que o ensino não deve estar focado na resolução de exercícios, nem na memorização, mas nos modos de se produzir conhecimento científico e no processo histórico relacionado a sua produção, como forma de gerar uma compreensão mais ampla dos conceitos científicos e de sua importância para a sociedade. Em relação ao Ensino de Matemática, Guy Brousseau afirma "que o fundamental é entrar na cultura matemática" (GURGEL, 2009, s/p.), defendendo que o ensino não deve se ater somente aos conteúdos, mas "a linguagem e o jeito de fazer a disciplina". Nas palavras de Brousseau, "Se todos tiverem acesso à cultura matemática, sabendo elaborar perguntas e hipóteses como fazem os profissionais da área, será mais fácil que exijam explicações e discutam se determinada justificativa é verdadeira ou falsa" (GURGEL, 2009, s/p.) .

Em maior ou menor grau, ao abordar os pontos discutidos na literatura acerca da natureza da Ciência, acabamos por propor um ensino que saia das fronteiras rígidas de cada disciplina e leve aos alunos a possibilidade de se atentarem para o modo de se fazer Ciências e Matemática, as possíveis conexões entre as distintas áreas de conhecimento e a historicidade das Ciências e da Matemática. Propõe-se que o aluno não deva conhecer somente os conteúdos científicos e matemáticos, mas também o modo como os cientistas e matemáticos produzem conhecimento. Isso envolve as linguagens, os modos de pesquisar (elaborando perguntas, testando hipóteses, coletando e analisando dados e definindo os resultados), as maneiras de raciocinar, a diversidade de métodos e argumentos utilizados para validar os conhecimentos produzidos e as demandas históricas e culturais de produção das Ciências e da Matemática.

\section{Dimensão sociocultural da abordagem histórica}

Consideramos que a História das Ciências e da Matemática tem o potencial de levar para a sala de aula discussões a respeito do desenvolvimento destas disciplinas em uma perspectiva sociocultural. Isso vai ao encontro do quarto aspecto - a saber, a Ciência é influenciada pelo contexto social, cultural, político etc., no qual ela é construída - apresentado por Moura (2014) sobre a importância da abordagem da natureza da Ciências em sala de aula.

\footnotetext{
3 Os trechos citados se referem a uma entrevista concedida por Brousseau à revista Nova Escola a respeito de sua teoria das Situações Didáticas.
} 
Deste modo, o professor tem a possibilidade de desenvolver em seus estudantes a percepção de que a prática científica não é neutra, tampouco isenta de interesses.

No âmbito da chamada História Cultural das Ciências valoriza-se a "dimensão cultural dos estudos históricos sobre a ciência, ou seja, suas práticas, representações, significados, instituições, contradições e contextos próprios" (ALVIM; ZANOTELLO, 2014, p. 353). "Os cientistas não somente falam, não somente dizem que fazem coisas, mas também as fazem" (PIMENTEL, 2010, p. 420, tradução nossa). Não podemos pensar na prática cientifica e matemática como algo isolado, mas como uma cultura construída e praticada pelos seres humanos e inserida em nossa sociedade. "Todo feito científico, toda teoria ou toda prática relacionada com o conhecimento da natureza é um feito profundamente cultural. Tal e como também é um feito social" (PIMENTEL, 2010, p. 418, tradução nossa). Nesta mesma perspectiva, Moura e Guerra (2016, p. 740), apontam para a inserção da História Cultural das Ciências no ensino:

Utilizar a História da Ciência Cultural no Ensino de Ciências implicaria, portanto, o desenvolvimento de narrativas históricas para o ensino que deslocassem de seu núcleo principal os grandes nomes da ciência e como estes atuaram para o estabelecimento de novas teorias, colocando em seu lugar as práticas científicas e como estas mudaram ao longo do tempo, além de como elas atuaram para alterar o conhecimento cientifico em si (MOURA; GUERRA, 2016, p. 740).

Porém, o modo como as Ciências e a Matemática são praticadas, ensinadas e divulgadas acaba por colocar tais disciplinas em um patamar superior e diferenciado. Isso reforça não somente a ideia de "gênio", mas também causa uma falsa impressão de que as Ciências e a Matemática não fazem parte da realidade cotidiana das pessoas. Essas visões estereotipadas refletem no modo como os estudantes encaram as aulas de Ciências e de Matemática gerando dificuldades de aprendizagem (GIL PÉREZ et al., 2001; HARRES, 1999; KAMPOURAKIS, 2016; LEDERMAN, 1992; OLIVEIRA, 2020; TABER, 2013; VOSNIADOU, 2019).

Essa dificuldade de compreensão dos conteúdos pode ser reflexo de relações hierárquicas estabelecidas entre o conhecimento ensinado no ambiente escolar e os saberes dos estudantes. Paulo Freire (1974, p. 63) afirma que quando as relações entre educador e educando são "fundamentalmente narradoras, dissertadoras" implicam em um sistema de ensino em que "o educador é o que sabe; os educandos, os que não sabem”. Deste modo, os últimos acabam por serem considerados "seres da adaptação, do ajustamento", que no máximo "têm a ilusão de que atuam", mas que, na verdade, tem seus saberes deslegitimados. Neste cenário, sem perceberem, os estudantes acabam por se acostumar à realidade imposta a eles, sem terem a oportunidade de atuarem questionando, interferindo e transformando o mundo ao seu redor (FREIRE, 1974, p. 67-68). Para Freire é preciso buscar formas de incentivar os indivíduos a pensarem criticamente e atuarem no mundo que os cercam. Deste modo, defende uma educação problematizadora na qual torna-se primordial a percepção dos 
estudantes "como estão sendo no mundo com que e em que se acham" (FREIRE, 1974, p. 82, grifos do autor). Isto só pode ser feito no momento em que se considera o educando como produtor de conhecimento.

Para nos aprofundarmos na ideia de que o educando é produtor e portador de conhecimentos e que estes muitas vezes são silenciados e deslegitimados pela prática educativa vigente, nos remetemos ao conceito - defendido por Boaventura de Sousa Santos (2002; 2011) - de sociologia das ausências que tem como "[...] objetivo mostrar que o que não existe é, de fato, ativamente produzido como não-existente, ou seja, como uma alternativa não credível ao que existe" (SANTOS, 2011, p. 30, tradução nossa). As ausências são produzidas através de uma racionalidade monocultural que nos evidenciam os motivos que geram e perpetuam os silenciamentos de saberes e de ideias que não se encaixam nos critérios de verdade impostos pelas Ciências e pela Matemática eurocentradas (SANTOS; ARAÚJO; BAUMGARTEN, 2016). Dentre as possíveis monoculturas elencadas pelos autores, destacaremos àquelas relacionadas ao saber, ao tempo linear e à naturalização das diferenças. Conforme apresentam abaixo,

A monocultura do saber e do rigor do saber cria o ignorante, a monocultura do tempo linear determina o residual, a monocultura da naturalização das diferenças legitima a classificação do inferior, a monocultura do universalismo abstrato demarca o que é local e estabelece a sua irrelevância e a monocultura dos critérios de produtividade capitalista decreta o improdutivo (SANTOS; ARAÚJO; BAUMGARTEN, 2016, p. 16).

Assim, enfocaremos as três primeiras formas de monoculturas que justificam lógicas de ausências que consideramos relevantes para fundamentarmos a dimensão sociocultural da abordagem histórica nas aulas de Ciências e de Matemática.

Santos (2011) considera que a lógica da produção de ausências mais poderosa é a monocultura do saber e do rigor do saber, na qual a dita ciência moderna e a alta cultura são transformadas em critérios únicos de verdade e de qualidade estética, respectivamente. Deste modo, todo conhecimento que o cânone não legitima, não reconhece e não valida é tratado como inexistente e essa não existência acaba por assumir a forma de ignorância e de incultura. Neste cenário, a sociologia das ausências busca resgatar os saberes e conhecimentos obscurecidos por esta monocultura, valorizando diferentes formas de interpretação e práticas de conhecimento.

Neste domínio, a sociologia das ausências visa substituir a monocultura do saber científico por uma ecologia de saberes. Esta ecologia de saberes permite, não só superar a monocultura do saber cientifico, como a ideia de que os saberes não científicos são alternativos ao saber científico. A ideia de alternativa pressupõe a ideia de normalidade e esta, a ideia de norma, pelo que, sem mais especificações, a designação de algo como alternativo tem uma conotação latente de subalternidade (SANTOS, 2002, p. 250). 
A ecologia dos saberes representa a possibilidade de diálogo entre os conhecimentos e práticas produzidas por sociedades diversas. A heterogeneidade de culturas, sociedades e saberes deveria ser inserida na realidade escolar, sendo um caminho possível sua proposição através da concepção da ecologia dos saberes. Esta apresenta-se com uma possibilidade de emergência, ao articular diferentes tipos de conhecimentos de diferentes sujeitos históricos, promovendo a diversidade cognitiva. Aqui entende-se que "Toda experiência social produz conhecimento" (SANTOS; MENESES, 2009, p. 9).

Para Santos e Meneses (2009, p. 11-12), a institucionalização das Ciências conferiu a mesma uma exclusividade sobre o conhecimento válido, tornando difícil a criação de ambientes de diálogo com outros saberes. Porém, é imprescindível “[...] o reconhecimento de conhecimentos rivais dotados de critérios diferentes de validade", tornando visíveis "[...] espectros muito mais amplos de acções e agentes sociais".

No âmbito da sociologia das ausências, outras lógicas também são importantes para a discussão aqui iniciada, especialmente as monoculturas do tempo linear e da classificação social. Os discursos de progresso, revolução, modernização, desenvolvimento, crescimento, globalização acabam por formular e fundamentar a monocultura do tempo linear, na qual seguem à frente "[...] os países centrais do sistema mundial e, com eles, os conhecimentos, as instituições e as formas de sociabilidade que neles dominam" (SANTOS, 2002, p. 247). Essa lógica coloca tudo aquilo que não atingiu os ditos patamares avançados como atrasado, prémoderno, obsoleto, subdesenvolvido, primitivo. É esta ideia que esconde as assimetrias dos tempos históricos e não valida a simultaneidade e as temporalidades próprias de cada povo. "Do mesmo modo, a presença ou relevância dos antepassados em diferentes culturas deixa de ser uma manifestação anacrónica de primitivismo religioso ou de magia para se tornar uma outra forma de viver a contemporaneidade" (SANTOS, 2002, p. 251).

Já a lógica da classificação social é reflexo da monocultura da naturalização das diferenças. Segundo Santos (2002, p. 252), "Embora em todas as lógicas de produção de ausência a desqualificação das práticas vá de par com a desqualificação dos agentes, é nesta lógica que a desqualificação incide prioritariamente sobre os agentes”. Ou seja, para além de negar os saberes e práticas que os sujeitos são protagonistas, aqui ele é inferiorizado. Isto é reflexo de uma cultura colonial que tende a classificar diferença como desigualdade. Na visão do autor (SANTOS, 2002, p. 252), criticar essa colonialidade é abrir “[...] espaço para a possibilidade de diferenças iguais - uma ecologia de diferenças feita de reconhecimentos recíprocos".

Outra proposta que valorizamos refere-se ao questionamento sobre o universalismo da ciência moderna. Este universalismo apresenta-se como um fenômeno ocidental, cuja hegemonia reside na supremacia dos interesses que o mantém. Enquanto colonizadores, o norte global produziu esta proposta universalista, numa tentativa de interpretação da multiplicidade do mundo, destruindo epistemologicamente o lugar das diversidades. Para tanto, os colonizadores se apropriaram dos conhecimentos e práticas locais, produzindo uma 
interpretação singular da natureza e do homem e, neste processo, criou-se uma relação de saber-poder, que hierarquizou os conhecimentos, silenciando aqueles que não participavam do modelo cognitivo "vencedor".

Desta forma, a normalização da ignorância - fazendo referência à monocultura do saber e do rigor do saber -, a análise anacrônica do outro - nos remetendo à monocultura do tempo linear - e a naturalização das hierarquias - no tocante à monocultura da naturalização das diferenças - são ideias envoltas de interesses sendo um dos principais a manutenção dos privilégios do opressor frente aos oprimidos. Do mesmo modo, a chamada Educação Bancária - que tem como tônica a transmissão de conhecimentos de forma acrítica - visa a manutenção de um sistema que coloca os oprimidos numa situação de inércia (FREIRE, 1974).

Consideramos que a abordagem histórica cultural das Ciências possibilita a percepção de que os saberes são múltiplos, diversos e partícipes de um processo políticosocial de silenciamentos e hierarquizações. Buscando uma ruptura com esta concepção, propomos a perspectiva da pluralidade ou diversidade epistêmica. Esta representa a multiplicidade de conhecimentos existentes que englobam a ciência moderna eurocentrada, mas extrapolam-na, permitindo pensarmos e conhecermos os processos históricos que constituíram outras formas de compreensão sobre a natureza, o homem e as técnicas. Sendo assim, a pluralidade epistemológica, "assenta na impossibilidade de identificar uma forma essencial ou definitiva de descrever, ordenar e classificar processos, entidades e relações no mundo. O próprio acto de conhecer (...) é uma intervenção sobre o mundo, que nos coloca neste e aumenta sua heterogeneidade" (SANTOS; MENESES; NUNES, 2005, p. 22-23).

No ambiente escolar, desconsiderar estes fatores é negligenciar a diversidade cultural e social de saberes. A segunda justificativa - que está numa dimensão sociocultural - trata justamente da importância da abordagem histórica em sala de aula como forma de desenvolver questões sociais e culturais do conhecimento científico e matemático, valorizando a diversidade e pluralidade epistemológica.

Segundo Miguel (1997), um dos mais importantes argumentos acerca da abordagem histórica em aulas de Matemática diz respeito, justamente, à possibilidade de um resgate cultural. Esta ideia perpassa relevantes discussões travadas no âmbito da chamada Etnomatemática que, na visão de Ubiratan D’Ambrósio (2001, p. 17), é uma área que busca “[...] entender o saber/fazer matemático ao longo da história da humanidade, contextualizado em diferentes grupos de interesse, comunidades, povos e nações”. Esta proposta articula o aspecto sociocultural do conhecimento à proposta de valorização da diversidade epistemológica.

Paulus Gerdes (1991) defende que a Matemática ensinada na escola não pode se restringir ao conhecimento produzido pelos homens brancos, mas considerar as distintas tradições como produtoras de conhecimento. Ainda, segundo o autor (GERDES, 1991), uma das possibilidades de justificar o baixo rendimento em matemática pode ser justamente essa falta de referência para o estudante: a necessidade de ter que aprender algo que lhe parece não 
ter conexão com sua realidade. Embora o ensino de Ciências e de Matemática tenha avançado bastante nas últimas décadas, uma das dificuldades encontradas pelos estudantes é a falta de conexão dos conteúdos aprendidos com suas realidades. Consideramos que essa falta de significado, muitas vezes, se relaciona ao fato de que os conhecimentos e a cultura dos estudantes são marginalizados e são impostos conhecimentos que, em certa medida, não dialogam na sua realidade. Nos termos de Boaventura (2011), a diversidade de conhecimentos, a ecologia dos saberes, não tem sido valorizada no ambiente escolar, colocando os conhecimentos eurocêntricos como foco e como únicas formas de saber válidos.

Para além de questionarmos uma visão eurocêntrica das Ciências e da Matemática, a abordagem de aspectos sociais e culturais também permite que os alunos percebam que tais conhecimentos são "[...] contingentes das condições sociais que governam sua construção" (KELLY; CARLSEN; CUNNINGHAM, 1993, p. 215, tradução nossa). Além disso, “[...] os valores socioculturais influenciam fundamentalmente o processo, o conteúdo e a aplicação" do conhecimento científico (KELLY; CARLSEN; CUNNINGHAM, 1993, p. 215, tradução nossa). A partir desta premissa é possível debater que os conhecimentos não surgem e nem são utilizados de maneira objetiva, mas interesses políticos e econômicos podem determinar o que se produz e o que não se produz.

\begin{abstract}
No ensino de ciências é fundamental considerarmos que o trabalho dos cientistas não ocorre à margem da sociedade em que vivem, sendo influenciado pelas variadas conjunturas de seu momento histórico. Isto torna fundamental a questão de como trabalhar os aspectos culturais e históricos da produção do conhecimento científico no ensino escolarizado das ciências (ALVIM; ZANOTELLO, 2014, p. $350)$.
\end{abstract}

Consideramos que a análise crítica sobre a historicidade das narrativas e ações de poder que produzem e determinam o que é ciência conferem aos alunos uma perspectiva reflexiva e emancipadora - como mostraremos na próxima seção -, ao romper com as monoculturas do saber e do poder, nos moldes das propostas de Boaventura de Sousa Santos (2002; 2011) e de Paulo Freire (1974), expressas acima. Toda ação e produção científica é sociocultural e/ou político-econômica, e seu ensino deve promover esta percepção e reflexão, especialmente se possui como objetivo a valorização da cidadania e criticidade em seus educandos. Ao fomentarmos a percepção sobre os saberes ausentes, o processo histórico de seu silenciamento e a instituição de monoculturas, estaremos realizando um ensino críticotransformador e problematizador, sendo a história das Ciências um espaço privilegiado para tais perspectivas no ambiente escolar.

Ao considerarmos os saberes dos estudantes e de seus antepassados, a escola tem o potencial de inseri-los em um ambiente complexo que envolve a reflexão crítica sobre a realidade, a discussão dos interesses e impactos das esferas política e econômica na produção e disseminação de conhecimentos e a percepção da importância da participação cidadã 
pessoal e coletiva nas decisões que envolvem, neste caso, conhecimentos científicos e matemáticos.

\section{Dimensão da práxis da abordagem histórica}

Freire (1974), em sua Pedagogia do Oprimido, para além das questões epistemológicas e socioculturais, adentra ao universo da práxis. Este termo, na abordagem freiriana, tem como objetivo estabelecer uma relação entre a interpretação e a reflexão da realidade e da vida e a prática que se origina da compreensão de mundo gerada por tal reflexão, prática esta que deve, consequentemente, possibilitar uma ação transformadora por parte dos educandos. Aqui também avançamos nesta discussão com o intuito de apresentar uma abordagem didática que, para além de valorizar os conhecimentos e interesses dos educandos como ponto de partida para o Ensino de Ciências e de Matemática, promova uma percepção da historicidade das Ciências e da Matemática, pois consideramos que esta perspectiva promove uma educação problematizadora e crítica fundada na prática originada da compreensão da realidade histórica.

Consideramos fundamental para o processo de construção do conhecimento pelo sujeito, a relação que ele estabelece entre os conceitos e o contexto em que vive, sua história e cultura, relação esta que tem, por natureza, um enfoque interdisciplinar. Ao focarmos, em nosso sistema de ensino, em conteúdos disciplinares, muitas vezes, perdemos a oportunidade de estabelecer conexões entre distintas disciplinas e também com os saberes que os próprios estudantes levam para a escola, o que justifica em boa medida a falta de sentido que muitos alunos atestam para os conteúdos apresentados nas aulas de Ciências e de Matemática.

Como tratamos anteriormente, o sistema educacional é histórico e cultural, lugar que se tornou um dos espaços de perpetuação das desigualdades (FREIRE, 1974). É na escola que a monocultura do saber tende a valorizar os conhecimentos provenientes da dita Ciência Moderna, e que por ter sido produzida por um grupo seleto de indivíduos, se sobrepõe e silencia outras formas de conhecimento (SANTOS, 2002; 2011). Contudo, segundo Freire (1974), é possível e se faz necessário realizar mudanças no sistema educacional, pois a escola tem a possibilidade de transformar as concepções de mundo dos indivíduos dominados fazendo-os refletir, agir e transformar o lugar social que ocupam.

Freire (1974), ao propor uma educação problematizadora, defende uma educação dialógica e libertadora: dialógica na medida em que educador e educandos consideram-se ambos sujeitos do processo educacional; libertadora pois, sendo fundamentada na reflexão e na ação, propicia ao educando a capacidade de intervir e transformar a realidade na qual está inserido. Na concepção freiriana, o diálogo implica num pensar crítico e vice-versa, "Sem ele não há comunicação e sem esta não há verdadeira educação" (FREIRE, 1974, p. 98).

Freire (1974), ao nos apontar como deveria se dar este processo metodológico de ensino, afirma que o mesmo necessitaria partir de temas geradores que seriam escolhidos em um ambiente de diálogo com os educandos. O ensino deve se iniciar a partir de temáticas 
mais genéricas próximas à realidade dos estudantes, das quais vai se isolando elementos - que o autor denominará de dimensões significativas - e aprofundando ideias específicas, com a finalidade de obter uma compreensão mais ampla sobre a totalidade proposta inicialmente.

A questão fundamental, neste caso, está em que, faltando aos homens uma compreensão crítica da totalidade em que estão, captando-a em pedaços nos quais não reconhecem a interação constituinte da mesma totalidade, não podem conhecêla. E não o podem porque, para conhecê-la, seria necessário partir do ponto inverso. Isto é, lhes seria indispensável ter antes a visão totalizada do contexto para, em seguida, separarem ou isolarem os elementos ou as parcialidades do contexto, através de cuja cisão voltariam com mais claridade à totalidade analisada (FREIRE, 1974, p. 113).

As dimensões significativas devem ser percebidas pelo educando como âmbitos da totalidade. Ao promovermos a investigação dos temas geradores, tem-se a possibilidade não só da apreensão da realidade por parte dos estudantes, mas sua inserção "[...] numa forma crítica de pensarem seu mundo" (FREIRE, 1974, p. 113), sendo que, "Investigar o "tema gerador' é investigar, repitamos, o pensar dos homens referido à realidade, é investigar seu atuar sobre a realidade, que é sua praxis" (FREIRE, 1974, p. 115).

A abordagem através de temas geradores pressupõe então a busca e criação de conhecimentos e, por isso, exige que os estudantes, conforme vão apreendendo significativamente acerca dos temas geradores e de seus encadeamentos, vão deixando os aspectos "focalistas" e se fixando na compreensão da totalidade. É neste sentido que Freire (1974) afirma que a educação problematizadora é também transformadora, pois quando o educando compreende e relaciona aquilo que está aprendendo com o que já sabe, ele tem a possibilidade de refletir e agir com vistas a transformar a realidade em que vive.

Neste sentido, concordamos com a percepção de Ivani Fazenda (2008, p. 21), para quem a interdisciplinaridade não é uma categoria diferenciada de conhecimento, mas um modo de ação e, embora haja uma interdisciplinaridade científica, a que nos interessa, neste momento, é aquela relacionada ao conhecimento escolar, no qual " [...] as noções, finalidades, habilidades e técnicas visam favorecer, sobretudo, o processo de aprendizagem, respeitando os saberes dos alunos e sua integração".

Quando o docente leva para a sala de aula uma abordagem histórica das Ciências e de Matemática, ele a deve utilizar como tema gerador, ou seja, como forma de fomentar relações entre temáticas mais genéricas e próximas à realidade dos estudantes a partir das quais os conteúdos disciplinares vão surgindo e tomando forma. Realidade do estudante é aqui entendida, conforme Freire (1974), como os aspectos relacionados ao ser humano em sua totalidade, como as relações sociais, políticas e econômicas que desenvolvem, mas também daquilo que caracteriza o ser humano como tal, diferenciando-o do animal. Freire (1974, p. 108) afirma que, diferentemente do animal, os seres humanos são "seres transformadores e criadores, em suas permanentes relações com a realidade" e é desta conexão que eles 
"produzem, não somente bens materiais, as coisas sensíveis, os objetos, mas também as instituições sociais, suas ideias, suas concepções. Através de sua permanente ação transformadora da realidade objetiva, os homens, simultaneamente, criam a história e se fazem seres histórico-sociais".

Ao trabalhar aspectos epistemológicos e socioculturais da prática científica e matemática de um ponto de vista histórico, o docente proporciona aos seus estudantes a oportunidade de compreender as Ciências e a Matemática como atividade humana integrada à sociedade e a essa permanente ação transformadora colocada por Freire (1974). Desta forma, os conteúdos científicos e matemáticos disciplinares vão sendo construídos pelo estudante de maneira significativa de modo que o mesmo perceba o papel social e cultural exercido por estas áreas de conhecimento no decorrer da história.

A terceira justificativa - que se encontra na dimensão da práxis - reforça as ideias de Freire (1974) e de Fazenda (2008), ou seja, a sala de aula deve se tornar espaço de aprendizagem a partir da realidade sociocultural, política e educacional dos alunos, buscando a formação de cidadãos reflexivos sobre a historicidade das Ciências e da Matemática e passíveis de transformarem sua realidade, através da cidadania científica e matemática.

Defendemos aqui a abordagem histórica como um tema gerador tendo em vista sua potencialidade de produzir importantes discussões em torno dos conteúdos científicos e matemáticos e de relacioná-los com a realidade e com os saberes dos estudantes, dos locais onde vivem e de seus antepassados. Esta abordagem permite a compreensão da complexidade da realidade em que estão inseridos, possibilitando ao educando uma participação cidadã frente aos problemas e temas que o cercam, incluindo aqueles que se relacionam às Ciências e à Matemática, assim como os reflexos que sentimos atualmente devido ao modo como estas áreas de conhecimento foram se consolidando historicamente.

O termo práxis é trazido justamente por que esta dimensão busca maneiras de valorizar a historicidade das Ciências e da Matemática como forma de gerar a cidadania científica e matemática (KRASILCHIK; MARANDINO, 2004; MOURA, 2012; SANTOS, 2008) que, consequentemente, tem a possibilidade de desencadear uma transformação social e cultural promovida pela ação dos próprios educandos. Deste modo, consideramos que a História das Ciências e da Matemática deve ser apresentada em sala de aula como forma de promover ao estudante a reflexão sobre a importância dos conhecimentos científicos e matemáticos para sua participação social e cidadã.

A dimensão da práxis também se remete à possibilidade de transformação da sociedade desigual em que vivemos, possibilitando ao educando uma percepção da construção histórica das desigualdades e dos silenciamentos, e de seu papel fundamental na mudança deste cenário opressor (FREIRE, 1974).

Nas palavras de Rossato (2018, p. 381), "a educação deve partir da realidade para compreender o homem e ser posta a seu serviço. Não pode ser reduzida a um conjunto de 
técnicas". Continuando, o autor afirma que "o objetivo principal é a compreensão e a interpretação do papel de cada educando no mundo", ou seja, deve-se ultrapassar o âmbito da reflexão gerando uma ação transformadora, ação que "se torna um ato político".

Ao apresentar a historicidade das Ciências e da Matemática como tema gerador, o professor tem o papel de:

[...] problematizar as explicações fornecidas, chamando a atenção e contrapondo distintas interpretações dos alunos, aguçando possiveis explicações contraditórias, procurar as limitações das explicações. A finalidade é promover o distanciamento crítico do aluno do seu conhecimento prevalente e enfim formular problemas que os alunos não formulam e, problematizadoramente, ao longo do processo educativo, desenvolver as soluções que o conhecimento científico a eles tem dado (DELIZOICOV, 1991, p. 179).

Exercitando o papel de mediador, o docente tem a possibilidade de demonstrar para seus estudantes que a história que nos é contada é aquela em que o discurso dominante "se põe diante da história como o seu único fazedor" (FREIRE, 1967, p. 51). Eles detêm "a História, para, assim, manter seus privilégios" (FREIRE, 1967, p. 55). A proposta de ecologia das temporalidades proposta por Santos (2002) se conecta aqui na medida em que, ao considerar uma diversidade de tempos presentes, não tratando os saberes do estudante como atrasado, valorizando e evidenciando os conhecimentos científicos e matemáticos de seu povo, cultura, dentro de sua própria história.

Segundo Freire (1967, p. 95), é necessário que o sistema educacional "desenvolva no nosso estudante o gosto da pesquisa, da constatação, da revisão dos "achados"” e isso só faz sentido se conectado à sua realidade, implicando no desenvolvimento de uma consciência crítica sobre o mundo. Reconhecer a produção e a prática de conhecimentos válidos dentro de suas próprias histórias é uma forma de valorizar os indivíduos e a trajetória de seu povo (CONTATORE; TESSER; BARROS, 2018; GERDES, 1991; KNIJNIK, 1996; PATZLAFF; PEIXOTO, 2009).

A abordagem histórica dos conhecimentos científicos e matemáticos aqui é chamada a ser usada como forma de problematizar as explicações fornecidas pelos estudantes e pelos seus antepassados na busca de uma compreensão mais profunda da constituição do conhecimento presente, através de uma reflexão crítica sobre o processo histórico da humanidade. Ou seja, a historicidade das ações humanas no tempo aparece em sala de aula como forma de oportunizar ao estudante como ele pode intervir e compreender sua realidade, tornando-o um sujeito histórico crítico. 


\title{
V. A abordagem histórica nas aulas de Ciências e de Matemática: uma proposta a partir do conceito de tempo
}

Vejamos como estas dimensões e suas respectivas justificativas aparecem em uma proposta temática: tomaremos como tema gerador o conceito de tempo. Como veremos, a ideia de tempo transcende as fronteiras disciplinares, tendo em conta sua presença, por exemplo, nas aulas de Matemática, Ciências, História, Geografia, Física e Filosofia.

O desenvolvimento da ideia de tempo reflete uma sensação ou consciência de duração quando relacionamos nossa experiência presente com o passado ou desejos futuros. E "embora nossa consciência do tempo seja produto da evolução humana, nossas idéias de tempo não são inatas nem automaticamente aprendidas, e sim construções intelectuais que resultam da experiência e da ação" (WHITROW, 1993, p. 18). Podemos pensar, então, na ideia de tempo como construção individual frente aos desafios de compreensão dos acontecimentos ao nosso redor para aos poucos ir percebendo a temporalidade.

\begin{abstract}
A aquisição gradual, pela criança, de conceitos temporais pode ser estreitamente correlacionada com o desenvolvimento de seu uso da linguagem. [...] No entanto, crianças pequenas tem dificuldade em adquirir urna concepção unificada do tempo, pois, mesmo quando começam a reconhecer seqüencias temporais, o tempo permanece dependente de suas próprias atividades. A aquisição gradual da linguagem, contudo, não só aumenta a capacidade da criança de compreender e de se comunicar como the permite apreender relações temporais e ampliar sua capacidade de conceituação temporal. Pois, embora possa parecer inerente a nossa experiencia pessoal, a consciência de fenómenos temporais envolve urna estrutura conceitual abstrata que. só gradualmente aprendemos a construir. (WHITROW, 1993, p. 18).
\end{abstract}

Sendo assim,

É necessário esclarecer a princípio, que o tempo é [...] [uma ideia] abstrata em virtude de não apresentar uma materialidade como o objeto ou o espaço, nem apresentar relações observáveis como a causalidade. É também, a categoria mais dificil de ser verificada no comportamento da criança. (RODRIGUES, 2007, p. 39, colchetes nossos).

Em outras palavras, "a noção do tempo histórico social, aquele que as sociedades humanas imprimem à época em que vivem, relacionando-o com o seu passado e o seu futuro, um tempo de simultaneidade de mudanças e permanências, é por demais abstrato e estranho à compreensão infantil”" (SCALDAFERRI, 2008, p. 53).

Para Rodrigues (2007) e Scaldaferri (2008), baseando-se nas pesquisas de Jean Piaget, uma das formas de iniciar o trabalho com crianças pequenas acerca da noção temporal é tornando-a concreta e relacionando-a, por exemplo, com a ideia de espaço e de velocidade, que por serem ideias reais e observáveis, facilitam esse trabalho inicial. "As duas principais 
operações que possibilitam o conceito de tempo são: a ordem (ou sucessão) dos acontecimentos (ou movimentos) e a imbricação das durações (intervalos entre os estados). São as operações fundamentais para a construção da noção temporal" (RODRIGUES, 2007, p. 40). Na visão piagetiana, as primeiras noções de tempo serão compreendidas à medida que a criança percebe que o curso das coisas gera uma transformação espacial, em que o amanhã se torna o hoje e o hoje se torna o ontem. Além disso, é importante que a criança compreenda que "entre um e outro estado sucessivo da sequência existe um intervalo que define a duração" e a imbricação das durações é justamente a percepção de que uma duração menor está contida pela maior (RODRGUES, 2007, p. 40).

As duas operações - a ordem e a imbricação das durações - são noções que darão à criança uma ideia qualitativa do tempo. Somente quando essas duas operações estiverem bem formadas na criança é que ela será capaz de compreender o tempo como medida, ou seja, uma ideia quantitativa do tempo. E "para construir os agrupamentos temporais métricos é necessário que a criança construa relações de isocronismo e sincronismo entre dois ou mais movimentos" (RODRIGUES, 2007, p. 46).

A ideia de tempo pode ser vinculada à noção de espaço, não somente como forma de estabelecer conexões para a aprendizagem das crianças, mas pode levar a reflexões acerca dos acontecimentos históricos que queremos explorar com os alunos e o fato de que, ao "voltarmos" no tempo, o espaço se reconfigura e toma novas formas (BITTENCOURT, 2009). Isso é muito importante, pois não basta, em uma aula de Ciências ou de Matemática, fazer uso da abordagem histórica, porém é preciso ter certeza de que o estudante compreende que os lugares não são estáticos e que falar de um século ou um milênio passado não somente envolve a mudança de tempo, mas a reconfiguração do espaço, assim como das estruturas sociais inerentes ao tempo e ao espaço do passado.

Especificamente nas aulas de História, sabemos que a noção de tempo é de suma importância, pois é nela que vai ser fundamentada a cronologia dos acontecimentos. Segundo Bittencourt (2009, p. 211), “[...] evidentemente que a localização dos acontecimentos no tempo de acordo com os critérios estabelecidos pelos historiadores é importante, mas não suficiente para o entendimento do tempo histórico". Segundo a autora, é importante dar referências para que o aluno não somente decore datas, mas compreenda os acontecimentos e as relações entre os fatos. Neste sentido, o ensino de História precisa estar vinculado ao que acontece antes, depois ou simultaneamente tornando o acontecimento como uma referência e dando significado e sentido ao que se quer explorar com o aluno (BITTENCOURT, 2009). Duas ideias importantes aqui presentes são as noções de sucessão e de simultaneidade.

Nas aulas de Matemática, a noção de tempo aparece no momento em que se ensina as unidades de medida. A noção histórica de tempo pode ser abordada, apresentando aos alunos os motivos pelos quais distintos povos sentiram a necessidade da medida e da padronização do mesmo (BRITO, 2016). Percebe-se na história do conceito de tempo uma necessidade de compreender como se organizavam as durações. 
No início da aprendizagem das unidades de tempo, o trabalho deve se focar na comparação com tempos na escala dos dias, meses ou de poucos anos como, por exemplo, fazer uma relação entre a idade do aluno com a de seus pais e avós. Deste modo, a ideia de tempo vai sendo construída com base naquilo que é próximo ao estudante até que ultrapasse estes limites.

Nas aulas de Ciências, a noção de tempo é fundamental para a compreensão de diversas ideias: na astronomia serve para a compreensão de fenômenos cíclicos, como os movimentos de rotação e de translação dos planetas e suas consequências, além de aspectos factuais, como o surgimento de vida no universo; na biologia, é utilizada para conhecermos o tempo de vida de plantas e de animais, assim como fenômenos cíclicos relacionados aos fenômenos físiológicos os ciclos circadianos; na geologia, para a compreensão da escala de tempo geológica e os acontecimentos em cada período; na física, para a compreensão de diversas ideias da mecânica, como a relação entre tempo e espaço para o estudo do conceito de velocidade, ou na compreensão do conceito de entropia, em que tempo é relacionado com energia. Como se pode perceber, esta abordagem auxilia o aluno a perceber a noção de tempo a partir dos ciclos naturais e biológicos, fenômenos debatidos tão largamente ao longo do desenvolvimento das Ciências.

Consideramos que neste ponto estão inseridos os debates acerca da natureza da Ciência, demonstrando como ela se transformou no decorrer da história. Podem-se explorar também outros aspectos presentes na produção científica como a instrumentação e as medições. A modelagem pode ser abordada por ter sido uma das formas de buscar uma compreensão de determinados fenômenos. As comunidades científicas, suas instituições, formas de negociação e seus protocolos podem ser trabalhados como forma de propiciar ao estudante momentos de compreensão de aspectos do dia a dia de um cientista (ACEVEDO et al., 2005; MOURA, 2014).

No ensino destas temáticas, nas aulas de Ciências, não basta fazer os estudantes decorarem os períodos e durações, mas também é necessário fazê-los compreender as relações entre elas e os impactos para o momento atual. Para isso, uma ideia bastante utilizada é a comparação de períodos de tempo através de outras escalas, como a transformação de unidades de tempo em comprimentos (CAVADAS; MESTRINHO, 2018).

A padronização das medidas de tempo fez surgir instrumentos para a realização destas medições - calendários, ampulheta, clepsidra, relógios de pêndulo, solar, digital e atômico são alguns exemplos. Todo este aparato nos mostra que os modos de registrar a duração do tempo foram mudando ao longo do tempo, como resultado de necessidades específicas de cada povo, de estudos científicos e das tecnologias que foram sendo desenvolvidas (SANTOS, 2014). Este debate nos coloca diante dos aspectos discutidos por Pimentel (2010) ao defender a História Cultural das Ciências, pois discute qual o papel dos instrumentos e das tecnologias em cada período histórico dentro do ambiente científico. 
A abordagem histórica do conceito de tempo permite ao professor da Educação Básica valorizar diferentes formas de conhecimentos de marcação e expressão de tempo produzidas historicamente. Dentre os distintos usos sociais do tempo, pode-se apresentar como distintas culturas faziam (e fazem) a contagem do tempo como os estudos de calendários indígenas (CARDOSO, 2007). Além disso, segundo Brito (2016), existe uma série de pesquisas acerca de diversas culturas e povos em que a noção de tempo não era utilizada, pelo menos, não da forma como a costumamos utilizar.

Bourdieu (1979) realizou pesquisas com camponeses cabilas, na Argélia e segundo ele, tais camponeses possuíam uma atitude de completa indiferença em relação à passagem do tempo, a pressa era vista como falta de compostura e até mesmo como uma "ambição diabólica". E. Thompson (1998), conta-nos dos nuers - uma confederação de tribos que vivem no sul do Sudão e no oeste da Etiópia - para os quais não existe uma expressão equivalente a "tempo" e, portanto, não podem falar dele como se fosse algo real. Os nuers organizam os acontecimentos por uma ordem lógica, não cronológica. Elias (1998) nos fala de sociedades em que não existe calendário, nelas não é possivel saber, sequer, qual a idade de uma pessoa (BRITO, 2016, p. 394).

Estes debates nos permitem ir além do conceito de tempo como conteúdo científico e matemático, mas percebendo-o como uma construção social e cultural. "Em diferentes sociedades, o tempo leva a criar hábitos - para alguns, sábado à noite é tempo de estar com amigos, final de ano é tempo para estar com a família, verão é tempo de ir à praia - e também disciplinariza o corpo - por exemplo, temos fome nos horários que nossas atividades diárias nos habituaram a comer" (BRITO, 2016, p. 391).

Para complementar a ideia de que o tempo aparece de diferentes formas na nossa sociedade, pode-se, em sala de aula, a partir do diálogo estabelecido com os estudantes, valorizar as formas utilizadas por eles e por seus antepassados para realizar a ação de medir e de comunicação do tempo. Este conjunto de abordagens pode servir como forma de valorização dos conhecimentos silenciados pelo colonialismo, evidenciando a ecologia dos saberes e das temporalidades, defendidas por Boaventura (2002). Neste sentido, a reflexão sobre os processos históricos que constituíram o apagamento dos saberes locais e a afirmação do universalismo da ciência eurocentrada promovem a percepção sobre quais destes conhecimentos foram considerados "verdadeiros" e como outros foram silenciados e inferiorizados.

Ao trabalhar a noção de tempo a partir de uma abordagem histórica, temos a possibilidade de nos inserir nas três dimensões discutidas anteriormente: no que diz respeito à dimensão epistemológica, podemos apresentar como o conceito de tempo e de medição de tempo foi se desenvolvendo historicamente nas práticas científicas e matemáticas; em relação à dimensão sociocultural, podemos refletir sobre os aspectos sociais e culturais que influenciaram o surgimento e o aprofundamento de tal conceito, assim como apresentar uma 
diversidade de saberes que foram sendo constituídos em torno de uma mesma ideia; e, por fim, esta temática permite adentrarmos na dimensão da práxis, já que o conceito de tempo é um tema gerador que abarca um conjunto amplo e interdisciplinar de ideias e temáticas das diversas disciplinas escolares.

\section{Considerações finais}

Como apresentamos anteriormente, nossa contribuição para as discussões a respeito das potencialidades da abordagem histórica com enfoque interdisciplinar no Ensino de Ciências e de Matemática apontam para três possíveis dimensões: epistemológica, sociocultural e da práxis. Consideramos as dimensões aqui apresentadas de extrema relevância para o Ensino de Ciências e da Matemática que busca uma educação problematizadora e crítica, pautada pela historicidade dos conhecimentos.

A abordagem histórica colabora com discussões que estão numa dimensão epistemológica, como a possibilidade de abordar questões relacionadas à natureza do trabalho científico e matemático (ACEVEDO et al., 2005; MOURA, 2014). Essa abordagem, além de promover uma compreensão das Ciências e da Matemática de modo integrado, permite apresentar alguns aspectos do trabalho científico e matemático como forma de inserção dos estudantes no universo destas disciplinas. Questões ligadas à teoria, observação/experimento e método, além da importância dos questionamentos, das hipóteses, das investigações e da argumentação são algumas das possibilidades de enfoque nas aulas. É possível discutir que, embora o cientista e o matemático sigam protocolos de trabalho e metodologias específicas, faz-se necessário que o estudante perceba que o fazer científico e matemático está submerso da subjetividade e da imaginação do pesquisador. Ademais, permite mostrar como a prática das Ciências e da Matemática se transformou ao longo da história, demonstrando que tais conhecimentos são dinâmicos e mutáveis. Como elucidamos anteriormente, a ideia não é estabelecer uma lista de concepções e ideias das Ciências e da Matemática, mas propiciar ao estudante a possibilidade de discutir e compreender as complexas tramas que permeiam o universo da prática e do desenvolvimento destas áreas de conhecimento.

A mutabilidade das Ciências e da Matemática é reflexo, em parte, de sua própria cultura, pois esta está repleta de significados e contextos próprios (MOURA; GUERRA, 2016; PIMENTEL, 2010), inclusive, dos interesses e das necessidades humanas, de cada cultura e sociedade, mostrando a não neutralidade do conhecimento científico e matemático. Aqui nos adentramos à dimensão sociocultural, valorizando aspectos - econômicos, políticos, religiosos, etc. - das Ciências e Matemática que auxiliam a desmistificar e desnaturalizar ideias estereotipadas destas disciplinas. A partir desta dimensão, a sociocultural, também questionamos a hegemonia da dita ciência moderna, em detrimento de outros saberes, tornando-se importante apresentar a diversidade de saberes proveniente de diferentes culturas e povos (SANTOS, 2002; 2011), incluindo aqueles trazidos pelos alunos e 
que refletem, inclusive, seus antepassados, auxiliando-os a se perceberem como produtores de conhecimento (FREIRE, 1974).

Consideramos também que a abordagem histórica nas aulas de Ciências e de Matemática deve ser pensada como um tema gerador (FREIRE, 1974) estreitando as conexões entre temáticas interdisciplinares e relacionadas à realidade dos estudantes com os conteúdos disciplinares. Ao trabalhar as Ciências e a Matemática de um ponto de vista histórico, o docente proporciona aos seus estudantes a oportunidade de compreendê-las como atividade humana integrada à sociedade. A dimensão da práxis tem como objetivo tornar a sala de aula espaço de aprendizagem a partir da realidade dos alunos, buscando a formação de cidadãos reflexivos sobre a historicidade das Ciências e da Matemática e passíveis de transformarem sua realidade, através da cidadania científica e matemática.

O quadro 2 resume cada dimensão segundo a justificativa de sua importância, os principais conceitos teóricos que utilizamos para embasá-las e os objetivos de cada dimensão para a inserção da abordagem histórica no Ensino de Ciências e de Matemática.

Como pudemos perceber, a partir das três dimensões, a abordagem histórica pode propiciar oportunidades de apresentar aos estudantes conexões que normalmente não estão claras nas ditas aulas tradicionais e disciplinares. Defendemos que as três dimensões sejam pensadas de modo indissociável na medida em que, cada uma com sua especificidade, depende da outra. A dimensão da práxis é necessária para que as duas outras - a saber, a epistemológica e a sociocultural - sejam colocadas em prática na sala de aula de modo efetivo. Por outro lado, as dimensões epistemológica e sociocultural fazem sentido se pensadas segundo o conceito de tema gerador debatido na dimensão da práxis, já que são tais temas que direcionarão as discussões em ambas as dimensões propostas.

Defendemos que a abordagem histórica se torna coerente quando se parte de uma temática ampla - próxima e do interesse do aluno - como forma de trabalhar a reflexão e a criticidade no ensino de Ciências e de Matemática. Além disso, as dimensões epistemológica e sociocultural estão, por natureza, integradas, no sentido de que tratar de aspectos históricos inerentes ao trabalho científico e matemático é, de algum modo, abordar questões sociais e culturais que interferem na prática e no desenvolvimento destas disciplinas.

É importante mencionar que algumas limitações desta propostas podem ser discutidas, como a pouca formação histórica dos licenciados nas áreas científicas e matemática ou, a ainda pequena quantidade de pesquisas publicadas com uma perspectiva historiográfica que evidencia a complexidade do desenvolvimento dos conceitos científicos e matemáticos, conforme mencionamos nas dimensões apresentadas e, como consequência, a falta de material didático que apresente esta discussão para os docentes em exercício de forma adequada (BELTRAN, 2009; FORATO; GUERRA; BRAGA, 2014; MIGUEL, 1997; SAITO, 2010). Contudo, sabemos que tanto o campo de pesquisa em História das Ciências e da Matemática, como os estudos históricos que buscam estreitar relações com o ensino vem ganhando força nos últimos anos, como podemos perceber através de trabalhos recentemente 
publicados (BELTRAN; TRINDADE, 2017; FIGUEIRÔA, 2019; GATTI; NARDI, 2016; OLIVEIRA; ALVIM, 2020; SILVA; PRESTES, 2013), ações que poderão minimizar algumas destas limitações.

Quadro 2 - Potencialidades da abordagem histórica nas aulas de Ciências e de Matemática.

\begin{tabular}{|c|c|c|c|}
\hline Dimensão & Justificativa & $\begin{array}{l}\text { Embasamentos } \\
\text { teóricos principais }\end{array}$ & Objetivos \\
\hline Epistemológica & $\begin{array}{l}\text { Natureza do } \\
\text { trabalho } \\
\text { científico } \\
\text { matemático }\end{array}$ & $\begin{array}{lr}\text { - Natureza da } & \text { Ciência } \\
\text { (LEDERMAN, } & 1992 ; \\
\text { MATTHEWS, } & 1995 ; \\
\text { EFLIN; } & \text { GLENNAN; } \\
\text { REISCH, } & 1999 ; \\
\text { ACEVEDO } \text { et al., } 2005 ; \\
\text { MOURA, } & 2014 ; \\
\text { SILVA; } & \text { PRESTES, } \\
\text { 2013; MARTINS, 2015) }\end{array}$ & $\begin{array}{l}\text { - Apresentar alguns aspectos do } \\
\text { trabalho científico e matemático } \\
\text { como forma de inserção dos } \\
\text { estudantes no universo destas } \\
\text { disciplinas; } \\
\text { - Mostrar como a prática das } \\
\text { Ciências e da Matemática se } \\
\text { transformou ao longo da história; } \\
\text { - Promover a compreensão das } \\
\text { Ciências e da Matemática de } \\
\text { modo integrado. }\end{array}$ \\
\hline Sociocultural & $\begin{array}{l}\text { Influências } \\
\text { sociais } \\
\text { culturais nas } \\
\text { Ciências e na } \\
\text { Matemática }\end{array}$ & $\begin{array}{lr}\text { - História Cultural da } \\
\text { Ciência (PIMENTEL, } \\
\text { 2010; } r \text { ALVIM; } \\
\text { ZANOTELLO, 2014; } \\
\text { MOURA, GUERRA, } \\
\text { 2016) } \\
\text { - Sociologia das } \\
\text { Ausências (SANTOS, } \\
\text { 2002; 2011) } \\
\text { - Educação } \\
\text { Problematizadora } \\
\text { (FREIRE, 1974) }\end{array}$ & $\begin{array}{l}\text { - Apresentar questões sociais e } \\
\text { culturais que influenciaram (e } \\
\text { influenciam) o desenvolvimento } \\
\text { das Ciências e da Matemática; } \\
\text { - Evidenciar que as Ciências e a } \\
\text { Matemática são uma prática } \\
\text { cultural; } \\
\text { - Mostrar que as Ciências e a } \\
\text { Matemática se desenvolvem de } \\
\text { modo interessado, ou seja, } \\
\text { aspectos econômicos, políticos, } \\
\text { religiosos, etc. impactam na } \\
\text { prática científica e matemática. }\end{array}$ \\
\hline da Práxis & $\begin{array}{l}\text { Metodologia de } \\
\text { ensino }\end{array}$ & $\begin{array}{l}\text { - } \quad \text { Tema Gerador } \\
\text { (FREIRE, 1974) } \\
\text { - } \quad \text { Interdisciplinaridade } \\
\text { (FAZENDA, 2008; } \\
\text { 1979; TRINDADE, } \\
\text { 2008; } \quad \text { BELTRAN; } \\
\text { TRINDADE, 2017) }\end{array}$ & $\begin{array}{l}\text { - Valorizar conhecimento e } \\
\text { interesses dos educandos como } \\
\text { ponto de partida para o Ensino } \\
\text { de Ciências e de Matemática; } \\
\text { - Promover o ensino de temas } \\
\text { geradores (interdisciplinares) } \\
\text { como foco para o ensino dos } \\
\text { diferentes conteúdos } \\
\text { (disciplinares). } \\
\text { - Fomentar a cidadania científica } \\
\text { e matemática através da } \\
\text { historicidade destas disciplinas. }\end{array}$ \\
\hline
\end{tabular}


De modo resumido, buscamos, ao somar as possibilidades expressas nas três dimensões, uma forma de promover aos estudantes um Ensino de Ciências e de Matemática que auxilie na compreensão dos conteúdos, na medida em que os mesmos compreendam que tais disciplinas: possuem uma gama de aspectos internos e externos mutáveis e passíveis de questionamentos; são fruto da atividade humana; sua produção e prática é influenciada por questões sociais e culturais; são influenciadas por interesses e valores que mudam e estão sujeitos à reorientações; podem ser pensadas e compreendidas de modo integrado; que os cientistas e matemáticos estão submersos neste universo.

A proposta apresentada acima apresenta como a História das Ciências e da Matemática é uma das possíveis formas de promover um espaço de debate reflexivo, considerado tão relevante para a formação dos estudantes. Ao problematizarmos os conteúdos disciplinares e mostrarmos como aspectos sociais e culturais influenciam no desenvolvimento e na prática das Ciências e da Matemática, o professor tem a oportunidade de auxiliar os estudantes a entenderem, não somente a importância e o sentido destes conteúdos, assim como ajudá-los a compreenderem criticamente e a transformarem a realidade na qual estão inseridos.

\section{Agradecimento}

O presente trabalho foi realizado com apoio da Coordenação de Aperfeiçoamento de Pessoal de Nível Superior - Brasil (CAPES).

\section{Referências bibliográficas}

ACEVEDO, J. A. et al. Naturaleza de la ciencia y educación científica para la participación ciudadana: Una revisión crítica. Revista Eureka sobre Enseñanza y Divulgación de las Ciencias, Cádiz, v. 2, n. 2, p. 121-140, abr. 2005.

ALVIM. M. H.; ZANOTELLO, M. História das ciências e educação científica em uma perspectiva discursiva: contribuições para a formação cidadã e reflexiva. Revista Brasileira de História da Ciência, Rio de Janeiro, v. 7, n. 2, p. 349-359, jul./dez. 2014.

BELTRAN, M. H. R. História da Ciência e Ensino: Algumas considerações sobre a Construção de Interfaces. In: WITTER, G. P.; FUJIWARA, R. (Orgs.). Ensino de Ciências e Matemática: análise de problemas. São Paulo: Ateliê Editorial, 2009. p. 179-208.

BELtRAN, M. H. R.; TRINDADE, L. S. P. História da Ciência e Ensino: abordagens interdisciplinares. São Paulo: Livraria da Física, 2017. 228 p. 
BITTENCOURT, C. M. F. Aprendizagens em História. In: BITTENCOURT, C. M. F. Ensino de História: fundamentos e métodos. 3. ed. São Paulo: Cortez, 2009. p. 181-222. cap. 2. $328 \mathrm{p}$.

BRITO, A. J. Tempo, História e Educação Matemática. Bolema, Rio Claro, v. 30, n. 55, p. 390-401, ago. 2016.

CACHAPUZ, A. et al. A Necessária Renovação no Ensino de Ciências. São Paulo: Cortez, 2005. $263 \mathrm{p}$.

CARDOSO, W. T. O céu dos Tukano na escola Yupuri: construindo um calendário dinâmico. 2007. 390 f. Tese (Doutorado em Educação Matemática) - Pontifícia Universidade Católica de São Paulo, São Paulo.

CAVADAS, B.; MESTRINHO, N. A medida do tempo geológico. In: PEIXOTO, A. et al. Educação em Ciências em múltiplos contextos - Atas do XVII Encontro Nacional de Educação em Ciências, I Seminário Internacional de Educação em Ciências, 2018. p. 358366. Atas... Viana do Castelo: Instituto Politécnico de Viana do Castelo. Escola Superior de Educação, 2018.

CONTATORE, O. A.; TESSER, C. D.; BARROS, N. F. Medicina chinesa/acupuntura: apontamentos históricos sobre a colonização de um saber. História, ciências, saúdeManguinhos, Rio de Janeiro, v. 25, n. 3, p. 841-858, jul./set. 2018.

COUTO, R. M. S. Fragmentação do Conhecimento ou Interdisciplinaridade: ainda um dilema contemporâneo? Revista Faac, Bauru, v. 1, n. 1, p. 11-19, abr./set. 2011.

D’AMBRÓSIO, U. Etnomatemática: elo entre as tradições e a modernidade. Belo Horizonte: Autêntica, 2001. 110 p.

DELIZOICOV, D. Conhecimento, Tensões e Transições. 1991. 214 f. Tese (Doutorado em Educação) - Faculdade de Educação, USP, São Paulo.

EFLIN, J. T.; GLENNAN, S.; REISCH, G. The nature of science: A perspective from the philosophy of science. Journal of Research in Science Teaching, v. 36, n. 1, p. 107-116, 1999.

FAUVEL, J.; MAANEN, J. V. (Eds.). History in Mathematics Education. The ICMI Study. New York/Boston/Dordrecht/London/Moscow: Kluwer Academic Publishers, 2002. 437 p. 
FAZENDA, I. C. A. Integração e Interdisciplinaridade no Ensino Brasileiro: efetividade ou ideologia. São Paulo: Loyola, 1979. 107 p.

FAZENDA, I. Interdisciplinaridade-Transdisciplinaridade: visões culturais e epistemológicas. In: FAZENDA, I. (Org.) O que é Interdisciplinaridade? São Paulo: Cortez, 2008. p. 17-28.

FIGUEIRÔA, S. F. M. (Org.). História e filosofia das ciências da natureza e da matemática: ensino, pesquisa e formação de professores. São Paulo: Edições Hipótese, 2019. $338 \mathrm{p}$.

FORATO, T.; GUERRA, A.; BRAGA, M. História das Ciências e Ensino de Ciências Historiadores das Ciências e Educadores: frutíferas parcerias e para um ensino de ciências reflexivo e crítico. Revista Brasileira de História da Ciência, Rio de Janeiro, v. 7, n. 2, p. 137-141, jul./dez. 2014.

FOUREZ, G. Crise no Ensino de Ciências? Investigações em Ensino de Ciências, v. 8, n. 2, p. 109-123, 2003.

FOUREZ, G. Abordagens Didáticas da Interdisciplinaridade. Lisboa: Instituto Piaget, 2008. 319 p.

FREIRE, P. Educação como Prática da Liberdade. Rio de Janeiro: Paz e Terra, 1967. 150 p.

FREIRE, P. Pedagogia do Oprimido. Rio de Janeiro: Paz e Terra, 1974. 218 p.

GATTI, S. R. T.; NARDI, R. (Orgs.). A História e a Filosofia da Ciência no Ensino de Ciências: a pesquisa e suas contribuições para a prática pedagógica em sala de aula. São Paulo: Escrituras Editora, 2016. 236 p.

GERDES, P. Etnomatemática: cultura, matemática, educação. Maputo: Instituto Superior Pedagógico, 1991.

GIL PÉREZ, D. et al. Para uma imagem não deformada do trabalho científico. Ciência \& Educação, Bauru, v. 7, n. 2, p. 25-153, 2001.

GÓMEZ-GRANELL, C. A Aquisição da Linguagem Matemática: símbolo e significado. In: TEBEROSKI, A.; TOLCHINSKI, L. (Orgs.). Além da Alfabetização: a aprendizagem 
fonológica, ortográfica, textual e matemática. Tradução: Stela Vieira. São Paulo: Editora Ática, 1997. cap. 11. p. 257-282.

GURGEL, T. Guy Brousseau: “A cultura matemática é um instrumento para a cidadania". Nova Escola, n. 228, 01 dez. 2009. Disponível em: <https://novaescola.org.br/ conteudo/545/guy-brousseau-a-cultura-matematica-e-um-instrumento-para-a-cidadania\#>. Acesso em: 26 mai. 2020.

HARRES, J. B. S. Uma revisão de pesquisas nas concepções de professores sobre a natureza da ciência e suas implicações para o ensino. Investigações em Ensino de Ciências, Porto Alegre, v. 4, n. 3, p. 197-211, dez. 1999.

JANTSCH, E. Towards Interdisciplinarity and Trandisciplinarity in Education and Innovation. In: APOSTEL, L. et al. (Eds.) Interdisciplinarity: problems of teaching and research in universities. Paris: Organization for Economic Co-operation and Development, 1972. p. 97-120.

JAPIASSU, H. Interdisciplinaridade e Patologia do Saber. Rio de Janeiro: Imago, 1976. $220 \mathrm{p}$.

KAMPOURAKIS, K. The "general aspects" conceptualization as a pragmatic and effective means to introducing students to nature of Science. Journal of Research in Science Teaching, v. 53, n. 5, p. 667-682, 2016.

KELlY, G. J.; CARLSEN, W. S.; CUNNINGHAN, C. M. Science Education in Sociocultural Context: perspectives from de Sociology of Science. Science Education, v. 77, n. 2, p. 207-220, 1993.

KIPNIS, N. A History of Science Approach to the Nature of Science: learning science by rediscovering it. In: MCCOMAS, W. F. (Ed.). The Nature of Science in Science Teaching: rationales and strategies. New York/Boston/Drodrecht/London/Moscow: Kluwer Academic Publishers, 2002. cap. 10. p. 177-196.

KNIJNIK, G. Exclusão e Resistência: educação matemática e legitimidade cultural. Porto Alegre: Artes Médicas, 1996. 139 p.

KRASILCHIK, M.; MARANDINO, M. Ensino de Ciências e Cidadania. São Paulo: Editora Moderna. 2004. 88 p. 
LEDERMAN, N. G. Student's and teacher's conceptions of the nature of Science: A review of the research. Journal of Research in Science Teaching, v. 29, n. 4, p. 331-359, 1992.

MARTINS, A. F. P. Natureza da Ciência no ensino de ciências: uma proposta baseada em "temas" e "questões". Caderno Brasileiro de Ensino de Física, Florianópolis, v. 32, n. 1, p. 703-737, dez. 2015.

MATTHEWS, M. R. História, Filosofia e Ensino de Ciências: a tendência atual de reaproximação. Cadernos Catarinenses de Ensino de Física, Florianópolis, v. 12, n. 13, p. 164-214, 1995.

MATTHEWS, M. R. History, Philosophy and Science Teaching: New Perspectives. New York: Springer, 2018. 354 p.

MIGUEL, A. As Potencialidades Pedagógicas da História da Matemática em Questão: argumentos reforçadores e questionadores. Zetetiké, Campinas, v. 5, n. 2, p. 73-106, 1997.

MOURA, B. A. O que é natureza da Ciência e qual sua relação com a História e Filosofia da Ciência? Revista Brasileira de História da Ciência, Rio de Janeiro, v. 7, n. 1, p. 32-46, jan./jun. 2014.

MOURA, C. B.; GUERRA, A. História Cultural da Ciência: Um Caminho Possível para a Discussão sobre as Práticas Científicas no Ensino de Ciências? Revista Brasileira de Pesquisa em Educação em Ciências, Belo Horizonte, v. 16, n. 3, p. 725-748, dez. 2016.

MOURA, M. A. Construção social da cidadania científica: desafios. In. MOURA, M. A. (Org.). Educação científica e cidadania: abordagens teóricas e metodológicas para a formação de pesquisadores juvenis. Belo Horizonte: UFMG / PROEX, 2012. p. 19-30.

OKI, M. C. M.; MORADILLO, E. F. O ensino de História da Química: contribuindo para a compreensão da Natureza da Ciência. Ciência \& Educação, Bauru, v. 14, n. 1, p. 67-88, 2008 .

OLIVEIRA, Z. V. A classificação das disciplinas matemáticas e a Mathesis Universalis nos séculos XVI e XVII: um estudo do pensamento de Adriaan van Roomen. 2015. $193 \mathrm{f}$. Tese (Doutorado em Educação Matemática) - Instituto de Geociências e Ciências Exatas, UNESP, Rio Claro. 
OLIVEIRA, Z. V. Concepções de matemática e implicações para a aprendizagem: um breve estudo. In: BOTO, C. et al. (Orgs.). A Escola Pública em Crise: inflexões, apagamentos e desafios. São Paulo: Editora Livraria da Física, 2020. p. 309-325.

OliveIRA, Z. V.; ALVIM, M. H. (Orgs.). Propostas Didáticas para o Ensino de Ciências e de Matemática: abordagens históricas. Santo André: Universidade Federal do ABC, 2020. $269 \mathrm{p}$.

PATZLAFF, R. G.; PEIXOTO, A. L. A pesquisa em etnobotânica e o retorno do conhecimento sistematizado à comunidade: um assunto complexo. História, ciências, saúdeManguinhos, Rio de Janeiro, v. 16, n. 1, p. 237-246, jan./mar. 2009.

PIMENTEL, J. ¿Qué es la historia cultural de la ciencia? Arbor. ciencia, pensamiento y cultura, v. 186, n. 743, p. 417-424, mai./jun. 2010.

PRESTES, M. E. B.; SILVA, C. C. (Eds.). Teaching Science with Context: historical, philosophical, and sociological approaches. New York/Heidelgerg: Springer, 2018. 464 p.

RODRIGUES, I. B. Estudo das Relações entre Desenvolvimento da Noção Temporal e Expressões Linguísticas de Tempo: a narrativa oral como proposta de intervenção em uma abordagem piagetiana. 2007. 172 f. Tese (Doutorado em Educação) - Faculdade de Filosofia e Ciências, UNESP, Marília.

ROQUE, T. Desmascarando a equação. A história no ensino de que matemática? Revista Brasileira de História da Ciência, Rio de Janeiro, v. 7, n. 2, p. 167-185, jul./dez. 2014.

ROSSATO, R. Práxis. In. STRECK, D. R.; REDIN, E.; ZITKOSKI, J. J. (Eds.). Dicionário Paulo Freire. 4. ed. Belo Horizonte: Autêntica, 2018. p. 380-382.

SAITO, F. História da Ciência e Ensino: em busca de diálogo entre historiadores e educadores. História da Ciência e Ensino: construindo interfaces, São Paulo, v. 1, p. 1-6, 2010 .

SANTOS, B. S. Para uma sociologia das ausências e uma sociologia das emergências. Revista Crítica de Ciências Sociais, Coimbra, n. 63, p. 237-280, 2002.

SANTOS, B. S. Um discurso sobre as ciências. 5. ed. São Paulo: Cortez, 2008. 92 p. 
SANTOS, B. S. Epistemologías do Sul. Utopía y Praxis Latinoamericana, Maracaibo, v. 16, n. 54, p. 17-29, 2011.

SANTOS, B. S.; ARAÚJO, S.; BAUMGARTEN, M. As Epistemologias do Sul num mundo fora do mapa. Sociologias, Porto Alegre, v. 18, n. 43, p. 14-23, set./dez. 2016.

SANTOS, B. S.; MENESES, M. P. (Orgs.) Epistemologias do Sul. Coimbra: Edições Almedina, 2009. $532 \mathrm{p}$.

SANTOS, B. S.; MENESES, M. P.; NUNES, J. A. Introdução: Para ampliar o cânone da ciência - a diversidade epistemológica do mundo. In: SANTOS, B. S. (Org.). Semear outras soluções: os caminhos da biodiversidade e dos conhecimentos rivais. Rio de Janeiro: Civilização Brasileira, 2005. p. 21-121.

SANTOS, L. R. Procedimentos e instrumentos para medir o tempo. In: SANTOS, L. R. Leon Battista Alberti (1404-1472) e a medida do tempo. 2014. 73 f. Dissertação (Mestrado em Educação Matemática) - Pontifícia Universidade Católica de São Paulo, São Paulo. p. 43-66.

SCALDAFERRI, D. C. M. Concepções de tempo e ensino de história. História \& Ensino, Londrina, v. 14, p. 53-70, ago. 2008.

SILVA, C. C.; PRESTES, M. E. B. (Orgs.). Aprendendo ciência e sobre sua natureza: abordagens históricas e filosóficas. São Carlos: Tipografia Editora Expressa, 2013. 561 p.

TABER, K. S. A Common Core to Chemical Conceptions: Learners' Conceptions of Chemical Stability, Change and Bonding. In: TSAPARLIS, G.; SEVIAN, H. (Eds.) Concepts of Matter in Science Education. Dordrecht: Springer, 2013. p. 391-418.

TRINDADE, D. F. Interdisciplinaridade: um novo olhar sobre as ciências. In: FAZENDA, I. (Org.) O que é Interdisciplinaridade? São Paulo: Cortez, 2008. p. 65-84.

VOSNIADOU, S. The Development of Students' Understanding of Science, Frontiers in Education, v. 4, p. 1-6, 2019.

WHITROW, G. J. O Tempo na História: concepções do tempo da pré-história aos nossos dias. Tradução: Maria Luisa X. de A. Borges. Rio de Janeiro: Jorge Zahar Editor, 1993. 242 p.

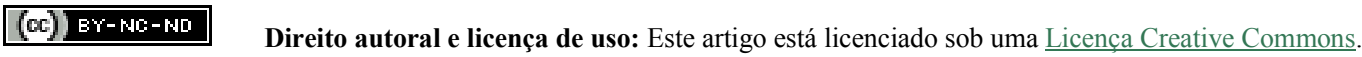

